
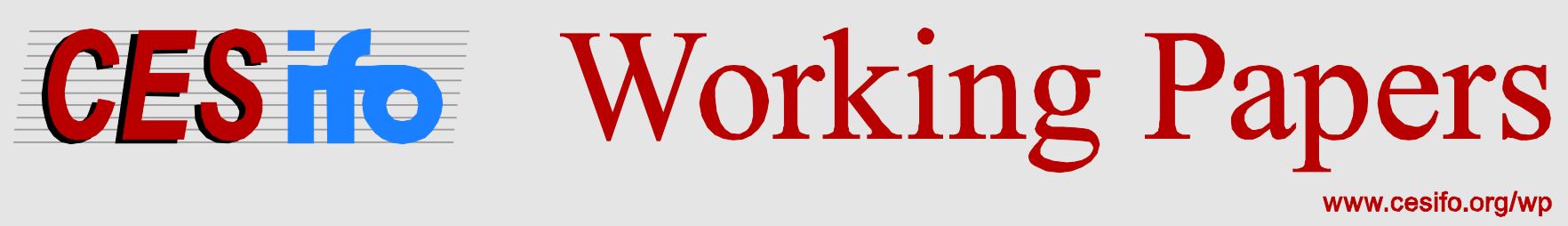

\title{
Do Market Incentives for Hospitals Affect Health and Service Utilization? \\ Evidence from PPS-DRG Tariffs in Italian Regions
}

\author{
Lorenzo Cappellari \\ Anna De Paoli \\ Gilberto Turati
}

CESIFO WORKING PAPER NO. 5804

CATEGORY 1: Public FinANCE

MARCH 2016

An electronic version of the paper may be downloaded

- from the SSRN website:

- from the RePEc website:

- from the CESifo website:

wWw.SSRN.com

Www.RePEc.org

www.CESifo-group.org/wp 


\title{
Do Market Incentives for Hospitals Affect Health and Service Utilization? Evidence from PPS-DRG Tariffs in Italian Regions
}

\begin{abstract}
We exploit variation across Italian Regions in the implementation of region-specific tariffs within a Prospective Pay System (PPS) for hospitals based on Diagnosis Related Groups (DRG) to assess their impact on health and on the use of health care services. We consider survey data for the years 1993-2007 with information on both individuals' perceived health and their utilization of health care services. Results suggest that the introduction of market incentives via a fixed-price payment system did not lead to worst health perceptions. Instead, it marked a moderate decrease in hospitalization coupled with a clearer decrease in the utilization of emergency services. We also find mild evidence of reduced satisfaction with health care services among hospitals patients. These effects were stronger for adoptions occurring when also the national government supported the market-based approach. Results are robust to a number of sensitivity checks.
\end{abstract}

JEL-Codes: I110, I180.

Keywords: health reforms, subjective health perceptions, utilization of health care services.

\author{
Lorenzo Cappellari \\ Department of Economics and Finance \\ Catholic University of Milan \\ Milan / Italy \\ lorenzo.cappellari@unicatt.it
}

\author{
Anna De Paoli \\ Department of Economics \\ University of Milan Bicocca \\ Milan / Italy \\ annasibilla.depaoli@gmail.com
}

\author{
Gilberto Turati* \\ Department of Economics \& Statistics \\ (ESOMAS), University of Torino \\ Italy-10134 Torino \\ gilberto.turati@unito.it
}

*corresponding author

Forthcoming at: Journal of the Royal Statistical Society - Series A

We thank Francesco Moscone, Jonathan Skinner and seminar participants at the IV Health Econometrics Workshop (University of Padua), the 2014 AIEL Conference (University of Pisa) and the 2014 EALE Conference (University of Ljubljana) for helpful comments. Usual disclaimers apply. 


\section{Introduction}

Over the past two decades, many European governments have been (re-)introducing the 'market mechanism' in the public health care sector in order to cope with various kinds of inefficiencies plaguing the hospital industry, which makes up nearly half of public health care spending. The Netherlands and the UK adopted the 'quasi-market' model for hospital services at the beginning of the 1990s. This model requires, on the one hand, a public purchaser to contract with public and private suppliers for the services offered to citizens; on the other hand, citizens are free to choose the producer from which to obtain the service they need. While supporters of market incentives underline the potential efficiency gains, opponents often worry about their negative impact on the quality of service provided and the health of patients.

Also Italy adopted the 'quasi-market' model at the beginning of the 1990s. The expected result was an improvement in efficiency, which could help the country, subject to a severe financial crisis, to meet the requirements imposed to public finances by the Maastricht Treaty. Besides modifying the organization of health care services delivery, the reform introduced a prospective payment system (PPS) based on Diagnosis-Related Groups (DRG), with nationally set tariffs. However, in Italy, unlike the UK where the National Health System (NHS) is highly centralized, regional governments were in charge of implementing the reform and could opt for setting their own tariffs in place of national ones. This led to regional variation in regulations and prices, and more market-oriented local governments set their own tariffs as a tool for targeting region-specific goals more efficiently.

What has been the impact of (quasi-)market incentives brought about by the PPS-DRG system on health outcomes and on services utilization? One concern is that hospitals reacted to more stringent economic incentives lowering the quality of the services they provide to meet quantitative targets; in the absence of systematic information and monitoring of service quality, this may have resulted in lower health outcomes for the population. Despite the centrality of the 
question for assessing the comparative merits of different models of health care organization, there is still no evidence on the topic in Italy and this paper represents the first attempt to provide an answer.

We consider the adoption of region-specific DRG tariffs in place of nationally-set ones as an indicator for the inclination of local governments towards using market incentives in health care. We exploit the differences between regions in the adoption (and timing among regions who did adopt) of region-specific tariffs to assess their impact on individual self-assessed health (SAH) and on measures of individual health services utilization. We use survey data for the years 1993-2007 with information on both individuals' perceived health and their utilization of health services.

Evidence on the impact of these pro-competitive reforms has been provided in recent years by a strand of literature reviewed in Gaynor et al. (2012). The general conclusion is that competition and, more generally, market incentives have a positive effect on health outcomes, in particular on the quality of health care services, but institutional details do matter. For instance, Propper et al. (2008), considering the first wave of reforms in the English NHS, find that hospitals in more competitive markets reduced the quality of care in order to cut waiting times. This result is explained by the fact that public information on quality was not available at that time, while waiting times were an important policy concern. Moreover, prices were negotiable between buyers and hospitals, and negotiations included results on waiting times, so that hospitals substituted less observable quality with more observable waiting times. Conversely, Cooper et al. (2011), considering the second wave of reforms in the UK, find that quality improved where competition was more fierce. This is due to the implementation of a new fixed-price funding mechanism called 'payment-by-results', largely mirroring the US PPS-DRG system, and to the provision of information about quality to patients.

We use a difference-in-differences approach which exploits variation in the implementation of region-specific tariffs in Italian regions. Regional governments could adopt the tariffs of the newly 
introduced national PPS, or they could set their own. Only eight out of twenty regions adopted their own set of tariffs in the years that followed, and only five did so in the very first years after the national reform, while three more regions introduced their own tariffs in the early 2000 s. This generates variations across regions and over time in the implementation of region-specific tariffs, which we use to identify the effect of the pro-competitive model on individual health and utilization of health care services.

Our results suggest that the introduction of market incentives does not lead to a worst health outcome despite the decrease in the utilization of services. In fact, while no significant changes emerge in $\mathrm{SAH}$, the adoption of regional tariffs marked a moderate decrease in hospitalization coupled with a clear decrease in the utilization of emergency services. These reductions in the utilization of health services are stronger if we restrict the analysis to the period when the quasimarket approach enjoyed full political support from the national government. We also consider a number of robustness checks and the potentially heterogeneous effects of the regional tariffs across different dimensions. In all cases our conclusions are largely confirmed. In addition, we find some evidence of reduced satisfaction with health care services among hospitals patients.

The paper unfolds as follows. In Section 2 we provide essential background information on the Italian quasi-market reform in health care. In Section 3 we describe the data and our identification strategy. Section 4 describes some basic patterns in the data while in Section 5 we present and discuss results from the econometric model. Section 6 concludes.

\section{The 'quasi-market' model in the Italian health system}

The Italian NHS is a regional health care system established in 1978. The central government is responsible for general legislation and financing of health care. Regional governments are instead in charge of organization, management and provision of health services. Therefore, even in the 
presence of national framework legislation, there exist territorial differences in the organization of health services, including the reimbursement mechanism for hospitals.

The introduction of quasi-markets is due to the 1992-1993 framework legislation, which was inspired by similar developments in the British NHS. The old Local Health Units (Unità Sanitarie Locali, USL; public bodies that jointly managed the tasks of insuring patients and of producing services) were transformed into Local Health Companies (Aziende Sanitarie Locali, ASL). These were more similar to private institutions and mainly focussed on administrative services, while production was transferred to the so-called Aziende Ospedaliere (AO, literally Hospital Firms), public hospitals quite similar to the NHS Trusts of the UK reform. ASL had to contract with producers and a price for the services to be purchased needed to be defined. The solution proposed by the central government was to introduce a PPS-DRG system, which basically substituted per-day fees for private providers and full ex-post payment for public hospitals with a fixed price reimbursement mechanism for both types of producers (see Turati, 2013).

A national listing of tariffs was set by the central government in 1994, but - coherently with the regional nature of the NHS - an opportunity was given to the twenty regional governments to adopt their own set of tariffs, and different regions reacted in different ways. Most of the regions simply adopted the national tariffs, but five introduced their own listings: Lombardy, Emilia Romagna, Tuscany and Umbria in 1997, followed by Veneto in 1998. All these regions belong to the Center-North of the country, traditionally characterized by more efficient local administrations compared to regions in the South.

The introduction of a region-specific set of tariffs is the key policy to implement the procompetitive reform designed in 1992-1993 by the national government. As observed by Di Loreto and Spolaore (2004), regional tariffs not only reflect production costs, but their adoption also signals the political willingness of providing incentives for pursuing region-specific goals in the supply of hospital services. National tariffs were set on the basis of data collected from eight 
hospitals only, mainly in the Center-North (Fattore and Torbica, 2006). It is unlikely that these could represent the operating costs of the population of Italian hospitals, and certainly were not ideal to incentivize local producers. On the contrary, local tariffs were tailored to the specific characteristics of regional hospitals. For instance, in Lombardy tariffs were set considering data from the majority of hospitals in the region, and were already available since 1994 (Fattore and Torbica, 2006).

Three other regions adopted their tariffs in the early 2000s: Sicily and Piedmont in 2002 and Lazio in 2005 (Carbone et al., 2006). However, the impact of using own specific tariffs for these three regions may have been mediated by other institutional changes that were implemented in the meanwhile, from the organization of the NHS to the regional funding of the system. Towards the end of the 1990sthe political orientation of the central government in health care management changed from a pure quasi-market model to a budget-based model aimed at capping public spending. The switch between models was enacted through Legislative decree 229/1999, with which the central government de facto denied the benefits of competition in health care. DRG-based payment systems for hospitals were not eliminated, but the quasi-market approach in health care began losing momentum. The practical implication of this process for our empirical analysis is that the effectiveness of region-specific tariffs might vary depending upon the era in which they were implemented, second half of the 1990s versus first half of the 2000s.

\section{[TABLE 1 AROUND HERE]}

Table 1 provides evidence of regional variation of DRG tariffs as of the late 1990s. Focusing on the group of early-adopting regions (adoptions occurring in 1997 and 1998) and on some specific DRGs, the Table reports regional tariffs resulting from a survey conducted by the National Agency for Healthcare Services (ASSR, 2003). Two main considerations emerge. First, there is a 
large variation in absolute prices. For instance, considering DRG 373 (vaginal delivery), the most common in terms of admissions, the comparison of tariffs across regions shows a range of more than 1050 euro, from 697.22 euro in Emilia Romagna (about 50\% lower than the national tariff) to 1750 euro in Umbria (with a mark-up of $17 \%$ above the national level). Similar conclusions emerge by looking also at DRG 371 (caesarean delivery) and DRG 134 (hypertension). The former is the closest alternative to vaginal delivery, but is considered an inappropriate treatment in the absence of any clinically necessary reasons. The latter is one of the 43 DRGs that the Italian legislation identified as being at risk of organizational inappropriateness, since hypertensive patients need not in general be hospitalized.

Second, regionally set tariffs reflect deliberate choices by local governments to provide incentives (or disincentives) to their hospitals. For instance, vaginal deliveries are always priced above caesarean sections, the relative price varying between 1.04 in the case of Lombardy and 2.38 in the case of Veneto. Moreover, looking at hypertension, all but one regional tariffs are below the national price, providing a clear disincentive to producers for potentially inappropriate treatments.

One shortcoming of market incentives in health care is that efficiency gains may occur at the expenses of quality, particularly in settings where there is little information and monitoring of service quality. Thus one may worry that regions introducing their own tariffs have reduced health outcomes of their residents. The analysis that follows investigates the impacts of regional tariffs on both service utilization and perceived individual health status.

\section{Data and identification strategy}

Our aim in this paper is to estimate the effects of market incentives on health outcomes and health service utilization, exploiting the adoption of region-specific DRG tariffs as the "treatment" capturing the exposure of the regional health system to market incentives. There are two margins of variation that we exploit for identification. First, while in total eight regions adopted their own 
tariffs, the remaining twelve did not, providing a source of variation. The second margin comes from differences in the timing of adoptions among the eight regions implementing their own tariffs, adoptions occurring over four different years (some regions adopted their tariffs in the same year).

The discussion of the last Section highlights that the choice of whether adopting or not region-specific tariffs and the timing of their implementation was left to local governments. As such, it was possibly determined by regional characteristics, including regional economic performance and political and cultural attitudes at the local level. In this paper we use data on individual-level outcomes of residents in the regions, so that the likely endogeneity of policy adoption that would emerge with regional-level outcomes is less of an issue in our case. One possible source of bias on individual-level data could stem from selective migration of individuals changing region of residence due to the adoption of local tariffs, but we see this instance as highly implausible.

\subsection{The Data}

We draw individual-level data from the Survey on the Daily Life of Italian Households (Indagine Multiscopo sulle Famiglie) which has been run annually (but for 2004) by the National Statistical Institute (ISTAT) since 1993. The survey covers a rich set of demographic controls, and provides information on several aspects of the everyday life of Italian households, from dwelling conditions to education, health status, use of health care services, labour market behaviour, transportation and time use. The sample is designed to represent the population of Italian households. The sampling unit is the household, and information is available both at the household and individual level. Each year, a sample of nearly 20,000 households (about 60,000 individuals) is interviewed. For the purposes of our analysis, we select individuals older than 15 and pool information over 14 waves (1993-2007), yielding an estimating sample of about 660,000 observations. Although publicly available data span through to 2012, we stop in 2007 due to a change in the wording of the question 
on SAH in 2008. While the change affected unconditional statistics, robustness checks on regression analyses including 2008-2012 data produced estimation results that were virtually identical to the ones presented in the paper. We use survey stratification weights throughout the analysis.

The survey contains identifiers of the region of residence which is crucial for our analysis because it enables us to determine whether respondents were exposed to region-specific PPS-DRG systems according to the survey year and region of residence, following the staggered-by-region pattern of own tariffs adoptions. In particular, our treatment is defined by the adoption at the regional level of a set or region-specific DRG tariffs as alternative to those defined at the national level. While these may represent only a part of a wider set of efficiency-increasing policy interventions, we consider their implementation as an indicator of the orientation of regional governments towards quasi-market mechanisms and price incentives for producers.

\subsection{Model specification}

We exploit differential adoptions across regions and time in an event study framework so as to allow both for treated-controls differences in trends before the adoption of region-specific tariffs, and for time varying effects of the adoption. Our baseline specification models the effect of the adoption of regional tariffs as follows:

$$
Y_{i r t}=\alpha+R_{r} \times \sum_{s=\tau(r)-2}^{s \geq \tau(r)+2} \beta_{s} I(t=s)+x^{\prime}{ }_{i r t} \gamma+\delta_{r}+\mu_{t}+\varepsilon_{i r t}
$$

where $i, r$ and $t$ stand for individuals, regions and years, respectively. $Y_{i r t}$ represents the individual outcome of interest; $R_{r}$ is a dummy indicating "treated regions" that adopted their own tariffs (there are eight such regions in total); $\tau(r)$ is the year in which region $r$ adopted its own tariffs; and the $I($ )s are indicators for exposure to the treatment, taking value one either in $\tau(r)$ or in the surrounding 
years, parameterising the event study specification. Our data start in 1993 and the earlier tariffs adoption occurred in 1997. In order to have at least two years of benchmark for the estimated effects, the event study specification uses as reference category time periods preceding the adoption by three or more years, thus in effect controlling for pre-existing trends in the two years prior to adoption. At the other end of the dataset, the last year of observation is 2007 while the latest adoption occurred in Lazio in 2005. We specify the last exposure indicator to be equal to one for time periods that follow adoption by two or more years. Note that since the survey was not conducted in 2004, in the case of Piedmont and Sicily the last treatment indicator (the one for $t \geq \tau(r)+2$ ) is only defined for periods following the treatment by three or more years, as those two regions adopted their own tariffs in 2002. Similarly, the treatment is not defined for Lazio in $t=\tau(r)-1$ because adoption occurred in 2005 in that case.

Remaining variables in the model are a set of controls for individuals' socio-demographic characteristics $x_{i r t}$ (age and its square, gender, education) and region and year fixed effects, $\delta_{r}$ and $\mu_{t}$, which ensure that the variation captured by the treatment indicators do not reflect time-invariant regional heterogeneity or secular trends common across regions. In the robustness section we also allow for the possibility of region-specific time trends. Finally, $\varepsilon_{i r t}$ is a white noise error term; in estimation we cluster standard errors by region so as to correct inference for correlation in the errors across time within regions. Since we have twenty regions, we tackle the issue of few clusters using wild bootstrap with 1000 replications.

The main parameters of interest in equation (1) are the coefficients $\beta_{s}$ associated with the treatment dummies. Conditional on the assumption of no difference in trends between treated (the residents of regions with $\left.R_{r}=1\right)$ and controls $\left(R_{r}=0\right)$ in periods preceding exposure $(t<\tau(r))$, a negative estimate of the $\beta$ s for $t \geq \tau(r)$ would imply that the introduction of region-specific tariffs exerted a detrimental causal effect on the outcome under investigation. 
The Multiscopo survey reports information about several variables that are of interest to our analysis as individual outcomes $Y$ and could have been affected by regional tariffs. Specifically, we focus our attention on SAH as main indicator of individual health status. SAH is a commonly used summary measure for general health and it has been shown to be strongly correlated with morbidity and mortality and with other objective measures of health, such as limitations in functioning, level of fitness and physical symptoms (Idler, 1992; Idler and Benyamini, 1997; Kennedy et al., 1998). Although SAH has been widely used in the literature, its ability in capturing true health status may be limited in a number of directions. For instance, Franks et al. (2003) show that self-rated health is systematically influenced by personal characteristics such as gender, age, ethnicity, education and income. Bauhoff (2011) illustrates that controlling for information on health issues makes in fact SAH more closely related to objective health, reducing respondents' overestimation of their own health status. In our study we will limit these biases controlling for all the socio-demographic factors available in the survey and also for habits that may potentially be related with individual health, such as smoking and drinking.

As the main target of PPS-DRGs was increasing efficiency in the use of health care, we study individual utilization of emergency room (ER) treatments, as well as ordinary hospitalization and day hospital treatments, for which we have information in the survey. We also consider satisfaction with the service for those hospitalized. In order to check whether regional tariffs induced individuals to substitute public health services with private ones -thereby compensating for any negative effect on health perceptions-we additionally consider indicators for whether at least one family member has a private health insurance. Since it is not clear from the questionnaire whether the insurance covers the household's head, all members or just some of them, the unit of analysis in this case will be the household and not the individual.

Finally, we complement the analysis with objective health indicators such as average life expectancy (ALE) and infant mortality rate (IMR), measured at the regional level, which are 
commonly used in the literature as proxies for health status (e.g., Piacenza and Turati, 2014; Baltagi et al., 2012, Hall and Jones, 2007, Papageorgiou et al., 2007, Crémieux et al., 2005, Shaw et al., 2005) and are made available by ISTAT in the Health For All Survey for the years 1993-2007.

\section{Descriptive statistics}

Table 2 offers a description of the estimating sample which is composed by all individuals older than 15. Column 1 considers the entire sample, whereas Columns 2 and 3 split the data by exposure status, depending on whether observations belong to region-year cells in which region-specific tariffs were effective (i.e., in this table a region adopting its own tariffs is counted as "Exposed to treatment" only in the adoption year and afterwards). Column 4 to 6 break up the data into three sub-periods: pre-adoption (1993-1996), first round of regional adoptions (the period with full support from the central government, 1997-1999) and second round of regional adoptions (20002007).

[TABLE 2 AROUND HERE]

The first outcome variable is $\mathrm{SAH}$, which is derived from a survey question asking respondents to rate their feelings about their overall health status on a 5-point scale, where 1 means "very bad" and 5 means "very good". We convert the original SAH variable into a binary indicator equal to one for scores equal to "good" (=4) or "very good" (=5) so that we can use linear probability models to retrieve the effects of the treatment on the likelihood of rating own health at least as good (a number of robustness checks shows that the particular way in which we re-code the SAH information is uninfluential on the analysis; they are available from the authors upon request). On average the health status does not vary much over time (columns 4 to 6) and over exposure status (columns 2 and 3). 
In Figure 1, Panel a), we represent the variation in average SAH over time and by treatment groups (defined by the values of $R_{r}$, meaning that an adopting region is counted as treated also before adoption). Time is measured as years since treatment so it corresponds to different calendar years for different treated regions. As in Table 1, evidence from Figure 1 shows no particular difference in SAH between treated and controls, despite the different ways in which we assign observations to the treatment in the two cases, time varying versus time invariant.

\section{[FIGURE 1 AROUND HERE]}

Besides SAH, we are also concerned with the utilization of health care services, which represent one of the main channels for the effectiveness of market incentives in making more efficient public spending, and analyse additional outcomes such as utilization of ER, day hospital (with information available only until 1999) and ordinary hospitalization. These outcomes are measured by binary indicators for having used the service in the three months prior to interview. For those that have been hospitalized we also look at an indicator of satisfaction with doctors during hospitalization, as a proxy for service quality. These are all outcomes that might react to market incentives. The descriptive statistics in Table 2 show indeed that exposure to treatment is associated with a decline of $2 \%$ in the utilization of ER and hospitalization; also, the proportion of those reporting themselves as satisfied with doctors (on a 3-point scale) is higher amongst the treated, $+8 \%$. The visual inspection of different trends in service utilization between treated and controls (Figure 1, Panels b) to d)) shows the most evident (unconditional) treatment effect is the one in to the use of ER, for which a positive difference that is prevalent in the four years prior to treatment, vanishes in the treatment year and afterwards. Evidence on hospitalization and day hospital, instead, is less supportive of the existence of any effect. Of course, these are unconditional estimates that do 
not control for region or time effects; we will adjust for these as well as for differences in the observable individual characteristics when estimating equation (1).

In Table 1 we can also notice that private insurance ownership slightly increased over time and in the treated regions; moreover, ALE and IMR, seems to be improving over time (Columns 4,5 and 6) and in treated regions (Columns 2 and 3).

\section{[TABLE 3 AROUND HERE]}

\section{Results and discussion}

\subsection{Baseline results}

Table 3 reports results from the estimation of equation (1) using as outcomes either SAH, health services utilization (ER, day hospital and hospitalization) and satisfaction with health care services. We estimate these regression controlling for demographics such as age, gender and education. We also considered alternative specifications that additionally control for health-related habits (smoking and drinking), employment status and type of occupation (to proxy income that is not available in the survey). As discussed in Section 3, personal attributes and health behaviours may affect the ability of SAH to proxy objective health status, and the additional controls can in principle alleviate the bias. However, as the inclusion of the additional controls did not alter the substance of our conclusions, we present results from the more parsimonious specification.

The model is estimated on three different samples. Panel A refers to the full sample; Panel B excludes late adopting regions (Piedmont, Sicily and Lazio) because for them adoption occurred in the context of a reduced political support for the quasi-market model at the national level, which may attenuate the effects of incentives provided by the quasi-market model; Panel $\mathrm{C}$ considers only the period up to 1999 , which has data on day hospital utilization and corresponds to the era of full support by the central government. 
Estimates in Panel A show no significant effect of regional tariffs adoption on SAH. We see some reduction in the year preceding the adoption, which vanishes in the years that follow, so that it seems fair to conclude that regional tariffs did not affect subjective health perceptions. Evidence from Panel B confirm this result. When we consider in the sub-sample that stops at 1999 (Panel C) we find a significant positive effect of 1.9 percentage points (p.p.) in the longer term (i.e. periods that follow adoption by more than one year), corresponding to $2.6 \%$ of the average $\mathrm{SAH}$ in the sample. Also this latter evidence does not support the idea that introducing region-specific tariffs worsens individual health outcomes, at least their perceptions.

The evidence on ER utilization is radically different, see Column 2 of Table 3. In the full sample (Panel A) we see a reduction of 2 p.p. (corresponding to $25 \%$ of the sample average) which occurs only in the longer run. Excluding late adopters (Panel B) magnifies the effect, which becomes of about 4 p.p. and now is apparent since the year of adoption of regional tariffs and remains stable in subsequent years. Restricting the sample to cover only the 1990s (Panel C), produces an equally persistent effect, although somewhat smaller (around -3.2 p.p.). This evidence suggests that regional tariffs did reduce utilization of ER in the medium/log-run, and this effect was stronger for regions adopting the quasi-market model in the years in which that approach also enjoyed political support at the national level.

Evidence on general hospitalization (Column 4 of Table 3) is in some sense similar to the one seen for ER. In the full sample no significant effect of regional tariffs adoption can be seen (Panel A). However when we exclude late adopters from the sample (Panel B), the effect increases, even though the estimates are not significantly different from zero according to the usual confidence levels. When we restrict the time window to the 1990s (Panel C), a negative, sizeable (about -1.2 p.p., or $25 \%$ of the sample average) statistically significant and persistent effect of regional tariffs adoption emerges. There is also some evidence of an anticipation effect in the year prior to 
adoption, which could depend on the fact that some regions may have started applying their own tariffs even before officially adopting them.

Column 3 of Table 3 reports in Panel $\mathrm{C}$ evidence about utilization of day hospital (the variable is available only up to 1999). In this case we do not see any significant effects from the adoption of regional tariffs. Finally, results on the satisfaction of those hospitalized with the services provided by doctors (Table 3, Column 5) suggest that this might have been negatively affected by the adoption of regional tariffs, at least in the long run. This effect is of about -5 p.p. on the probability of reporting oneself as satisfied on a 3-point scale, corresponding to roughly 15 percent of the sample average, and occurs only in the long run, i.e. it is evident only for the treatment indicator corresponding to two or more years since adoption. One likely channel for this effect is the reduction in the average duration of hospitalization spells, which might have impacted negatively on service quality perceived by those hospitalized.

Overall, these results show that while SAH remains unchanged, the use of health care services is reduced substantially, possibly meaning that prior to the adoption of regional tariffs the use of health care services was inappropriate with respect to actual needs. The market incentives triggered an improvement in the efficiency of health spending, and there is some evidence that this occurred contextually with a reduction in satisfaction for those experiencing hospitalization.

\subsection{Robustness checks}

In what follows we assess in different ways the robustness of the findings obtained thus far. First, we amend the baseline specification adding region-specific trends, so as to relax the common trend assumption underlying the results in Table 3; we also extend the baseline model with a more flexible specification of treatment effects to capture longer term effects. Then we consider ALE and IMR, to see whether the absence of effects on health also applies to objective measures of health conditions. Since ALE and IMR data are defined at the regional level, we will repeat also the 
baseline analysis of Table 3 on data aggregated at the regional level to provide a benchmark. Next we look at the effects of regional tariffs on private health insurance ownership, as individuals may have substituted publicly provided services with private ones. Finally, we conduct the main analysis by birth cohort to see whether the aggregate effects reflect differences across individuals that grew up under different national health policy regimes (in particular young cohorts growing up with the Italian NHS established in 1978). We conduct these robustness checks on the full sample but for the case that has day hospital utilization as outcome, for which the time window stops in 1999 by necessity.

Region-specific trends and longer term effects. Our baseline specification controls for year and region fixed effects, but there might exist region-specific trends in SAH and in the use of health care services that could confound the impacts of region-specific tariffs and that we are not capturing with the baseline model. For example, in treated regions individuals may modify the subjective evaluation of their health status changing their reference point and adapting it to what they perceive to be the standard for health conditions. In this circumstance, our analysis would not reveal any negative impact on SAH even if individuals' health status actually deteriorated.

\section{[TABLE 4 AROUND HERE]}

To account for these possibilities, we augment the baseline specification of equation (1) with interactions between regional dummies and a linear trend. The results are reported in Table 4, Panel A, and show that the impact of region-specific tariffs on hospitalization is stronger compared to the baseline, with some mild evidence of an anticipation effect. At the same time, the evidence for SAH confirms the baseline results of no detrimental effect of tariffs adoptions.

In our baseline specification the latest treatment effect is estimated for periods that follow regional tariffs adoption by two or more years. Since the last adoption occurred in Lazio in 2005 
and the data stop in 2007, treatment effects specified three or more years after adoption would have not been defined for that region. Our choice of treatment definition that pools all years since the second after treatment is therefore aimed at finding a specification that applies to all regions. Still, it is of interest to see if and how treatment effects distinctively evolve in the longer run three or more years after the adoption. We provide such evidence in Panel B of Table 4, where we use the sample that excludes late adopters and use a more flexible specification of treatments, which allows for separate effects in each of the five years following adoption and pools effects in the sixth year since adoption or later. We do not consider day hospital utilization because data on this outcome are available only since 1999, which follows adoption by a maximum of two years for the group of regions adopting their tariffs in the 1990s. Results (to be compared with Panel B of Table 3) point towards the stability of the negative effects on ER utilization. On the other hand, the negative effect on satisfaction with doctors of those who were hospitalized seems to be less persistent; a possible explanation could be that individuals adapt to the new regime (in particular, the reduction in the average length of stay) after a few years regional tariffs are implemented.

Objective health measures. The survey data used in this paper do not contain information on objective indicators of individual health. Our health measure is subjective and there exist a large literature supporting the ability of SAH to proxy objective health conditions (see the discussion in Section 3). However one may still be worried that subjective feelings are incapable of tracking changes in health conditions over time in the face of changes in the institutional environment brought about by the decisions of local governments. The adaptation of reference points mentioned above exemplifies one possible source of attenuation bias that could plague the estimates of treatment effects on SAH. In order to gain some insights on this issue, in Table 5 we move to objective health indicators. In the absence of individual level data on these variables, we resort regional-level health indicators, in particular we focus on the IMR and the ALE. As discussed in Section 3, estimating the impact of regional treatments on individual outcomes mitigates the likely 
endogeneity of adoptions by regions; by using regional-level data we miss this opportunity, so that identification entirely relies on the ability of region-specific fixed effects and trends in absorbing the variation produced by confounders. On the other hand, the specific aggregate indicators we use do not suffer from biases due to endogenous survival which, in principle, might affect surveys data on individuals. Moreover, IMR is directly linked to variables under the control of hospitals, like the choice of vaginal versus caesarean delivery: Francese et al. (2014) provide evidence that DRG tariffs influence the inappropriate use of caesarean sections in the Italian NHS, and Table 1 clearly showed large variation in regional tariffs for the two treatments.

\section{[TABLE 5 AROUND HERE]}

Table 5 illustrates the effect of regional tariffs on these two objective health status indicators; to provide a benchmark, we replicate the analysis at the regional level also for the baseline outcomes of Table 3. First of all, considering the baseline outcomes (Columns 1 to 4) we can notice that for both the fixed (Panel A) or time varying (Panel B) specification of regional effects results are pretty much in line with their individual level counterparts in Tables 3 and 4, which suggests that biases coming from the use of regional-level data are not a major issue. Second, the only statistically significant impact that we can detect is a positive effect on ALE in the longer term, which is consistent with the results on SAH in indicating that the adoption of regional tariffs did not worsen health status.

Substitution of public with private services. One reasons of the apparent neutrality of regional tariffs for individual health is substitution of public health care services with private ones. Faced with increased difficulties in accessing public care, some may have reacted by resorting to private health services, so that for them preserving (perceived) health status at the pre-adoption levels was costly. This possibility can affect the interpretation of our results, as it would imply an impact of 
regional tariffs on household budgets. Since our data do not contain direct information on out-ofpocket spending and of the use of private services, we consider a binary indicator for the subscription of a private health insurance in the household as a proxy.

\section{[TABLE 6 AROUND HERE]}

Results are reported in Table 6 both for the specification with regional fixed effects (Column 1) and the one with regional trends (Column 2). In both specifications, we see some effects of regional tariffs and also some mild anticipation effects. In the specification with regional trends, the effects does not seem to be long lasting. Overall, the evidence suggests that effects operating via substitution of public health care with private health insurance have been relatively weak.

\subsection{Heterogeneity by birth cohort, education and region}

We now explore the heterogeneous effects of regional tariffs according to year of birth and educational attainment, so as to provide an understanding on whether the absence of effects on SAH is actually the result of opposing effect on different demographic group cancelling each other out. Also, we allow the treatment effect to vary by region to provide a sense of the geographical variation of the effects estimated with the baseline model.

A cohort-wise analysis. As briefly mentioned in Section 2, in 1978 there was a radical change in the organization of the Italian public health care service: a highly fragmented system of insurance funds - essentially a consequence of the corporative nature of the Italian Welfare State-was replaced by a public universalistic scheme. It is then interesting to explore if there are variations in individuals' health perceptions that depend on the different 'organizations' of the public health care schemes experienced over the lifetime. Individuals born before 1948 - and thus aged at least 30 in 1978 - are those that potentially used the health care services before 1978, and thus may react 
differently to regional tariffs with respect to those that did only experience the post-1978 health system.

\section{[TABLE 7 AROUND HERE]}

To investigate this possibility, we amend the baseline specification of equation (1) by introducing interactions between the treatment indicators and a dummy variable for individuals born before 1948. The results are in Table 7. Perhaps surprisingly, SAH improves with the treatment for those that were born before 1948, while it gets relatively worse for those born after 1978, although the latter does not seem to be a long lasting effect. The decrease in hospitalization is clearly driven by the older cohort, while ER utilization decreases mostly in the sample of younger individuals. Overall results do not show important differences in the way people react to regional tariffs, at least according to the organization of the health care system they experienced in their lifetime. It is worth noting that the older cohort that can compare the organization of the health system with previous 'regimes' is not the one reporting a deterioration in health status.

\section{[TABLE 8 AROUND HERE]}

Heterogeneity by education. Individuals with different levels of education (and hence, presumably, different cognitive skills and higher incomes) may react differently to changes in health care. For instance, more educated individuals might have a better understanding of the rationale of health policies compared with less educated ones, and can appreciate that a reduction in the average length of hospital stay need not necessarily translate into a general detriment for health. This, in turn, may increase the effectiveness of regional tariffs in this segment of the population. Also, educated individuals may perceive symptoms as more salient than the less educated do, which 
may induce some over-utilization of health care services (particularly emergency ones), generating a margin of inefficiency that regional tariffs may smooth out.

To explore this dimension of heterogeneity we divide our sample in three groups according to the highest level of education achieved: compulsory, higher secondary and tertiary education. Results are in Table 8. Results on SAH do not reveal any particular heterogeneity. On the other hand the reduction in ER utilization is more evident for individuals with secondary and, especially, tertiary education compared with individuals with only compulsory education. This supports the idea that education plays a role in shaping the gradient of reactions to regional tariffs.

\section{[TABLE 9 AROUND HERE]}

Heterogeneity by region. In Table 3 we have already provided evidence suggesting that the effects of adoptions were heterogeneous across regions, as we found their impacts to be the strongest for when excluding late adopters. Now we explore regional differences further and interact the treatment indicators with regional dummies. Results are reported in Table 9. Evidence on the regional distribution of treatment effects on $\mathrm{SAH}$ is somehow mixed, including regions with no effects (Piedmont) positive effects (Lombardy, Umbria) and negative effects (Veneto, Lazio and Sicily). With the notable exception of Veneto, these patterns seem to reflect the early/late adopters divide, with negative effects mostly concentrated among late adopters. Certainly, their existence highlights considerable heterogeneity behind the overall absence of effects characterizing the baseline specification. Instead, effects seems to be homogenous across regions is the case of ER utilization and, to some extent, hospitalization and use of day hospital, where all effects are negative, even though with some anticipations in some regions. There is only one region where the effect is positive, Sicily, one of the late adopters and a region characterized by a negative differential in terms of efficiency with respect to early adopters. Finally, patterns of satisfaction 
with doctors for those hospitalized do vary across regions, but anyway tend to confirm the nationallevel evidence of a slight decline of satisfaction.

\section{Concluding remarks}

This paper assesses for the first time the effects of market incentives for Italian hospitals on individual outcomes and behaviours. We focus on the introduction of DRG-based PPSs in the late 1990s and early 2000s; specifically we exploit the possibility to opt out from national tariffs and to introduce own tariffs offered to regional governments by the national law. Not all regions took this chance, and we use the adoption of regional tariffs as an indicator regional governments' promarket orientation in the hospital sector. Exploiting regional heterogeneity in tariffs adoptions and variation in the timing of adoption among adopting regions, we develop a difference-in-differences estimator of the effects of market incentives. We evaluate their impact on both self-assessed health $(\mathrm{SAH})$ and on reported utilization of health care services. Our headline findings indicate that while SAH was unaffected, the utilization of publicly provided health services was diminished.

These results, which are robust to a number of sensitivity checks, are consistent with the idea that in the absence of market incentives health care services were likely to be over-utilized by patients and that the introduction of regional tariffs has increased the overall efficiency of the health care system. Results also suggest that the effectiveness of market incentives at the local level crucially depends on the overall political support coming from the national government. The Italian government dismissed the quasi-market approach to health care management in favour of a budgetbased one as of the late 1990s, and the effectiveness of local tariffs was weakened for regions who adopted them in the years that followed. 


\section{References}

ASSR (2003), Le tariffe regionali per i 60 DRG più frequenti, Monitor, n. 7.

Baltagi B., Moscone F. and Tosetti E. (2012), "Medical technology and the production of health care”, Empirical Economics, 42(2), 395-411.

Bauhoff S. (2011), Systematic self-report bias in health data: impact on estimating cross-sectional and treatment effects, Health Services and Outcomes Research Methodology, Vol. 11(1-2), pp. 44-53.

Carbone, C., Jommi, C., A. Torbica (2006), Tariffe e finanziamento dell'innovazione tecnologica: analisi generale e focus su due casi regionali, in Anessi Pessina, E. and E. Cantù (eds.), Rapporto OASI 2006 - L'aziendalizzazione della Sanità in Italia, EGEA.

Cooper Z., Gibbons S., Jones S., McGuire A. (2011), Does hospital competition save lives? Evidence from the English NHS Patient Choice Reforms, Economic Journal, 121: F228F260.

Crémieux P-Y., Mieilleur M-C., Ouellette P., Petit P., Zelder P. and Potvin K. (2005), Public and private pharmaceutical spending as determinants of health outcomes in Canada, Health Economics, 14, 107-116.

Di Loreto P., Spolaore P. (2004), L'evoluzione del sistema nelle politiche regionali, in Falcitelli N. and Langiano T. (eds.), Politiche innovative del Ssn: i primi dieci anni dei Drg in Italia, Il Mulino.

Duggan, M. (2000), Hospital Ownership and Public Medical Spending, Quarterly Journal of Economics, 1343-1374.

Fattore G., Torbica A. (2006), Inpatient reimbursement system in Italy: How do tariffs relate to costs?, Health Care Management Science, 9, 251-258. 
Francese M., Piacenza M., Romanelli M., Turati G. (2014), Understanding Inappropriateness in Health Spending: The Role of Regional Policies and Institutions in Caesarean Deliveries, Regional Science and Urban Economics, 49, 262-277.

Franks P., Gold M. R., Fiscella K. (2003), Sociodemographics, self-rated health and mortality in the US, Social Science and Medicine, Vol. 56, pp. 2505-2514.

Gaynor M., Moreno-Serra R., Propper C. (2012), Can competition improve outcomes in UK health care? Lessons from the past two decades, Journal of Health Services Research \& Policy, 17: 49-54.

Hall R. and Jones C. (2007), “The value of life and the rise in health spending”, Quarterly Journal of Economics, 122, 39-72.

Idler E.L. (1992), Self-assessed health and mortality: a review of the studies, International Review of Health Psychology, 33-54.

Idler E.L., Benyamini Y. (1997). Self-rated health and mortality: a review of twenty-seven community studies. Journal of Health and Social Behavior, 38, 21-37.

Kennedy B.P., Kawachi I., Glass R. \& Prothrow-Stith D. (1998). Income distribution, socioeconomic status, and self-rated health in the United States: Multilevel analysis. British Medical Journal, 317, 917-921.

Papageorgiou C., Savvides A. and Zachariadis M. (2007), "International medical technology diffusion”, Journal of International Economics, 72, 409-427.

Piacenza M., Turati G. (2014), Does Fiscal Discipline towards Sub-national Governments Affect Citizens' Well-being? Evidence on Health, Health Economics, 23 (2), 199-224.

Propper C., Burgess S., Gossage D. (2008), Competition and quality: evidence from the NHS Internal Market 1991-9, Economic Journal, 118: 138-170.

Shaw J., Horrace W. and Vogel R. (2005), "The determinants of life expectancy: an analysis of the OECD health data", Southern Economic Journal, 71, 768-783. 
Turati G. (2013), The Italian Servizio Sanitario Nazionale: a renewing tale of lost promises, in J. Costa-Font and S. C. Greer (eds.), Federalism and Decentralization in European Health and Social Care: Competition, Innovation, and Cohesion, Palgrave MacMillan, 47-66. 
Table 1: Regional variation in tariffs on selected DRGs, 1999

\begin{tabular}{|c|c|c|c|c|c|c|c|}
\hline & \multicolumn{2}{|c|}{$\begin{array}{c}\text { (1) DRG } 373 \\
\text { Vaginal Delivery }\end{array}$} & \multicolumn{2}{|c|}{$\begin{array}{c}\text { (2) DRG } 371 \\
\text { Caesarean section }\end{array}$} & \multirow[t]{2}{*}{$\begin{array}{l}\text { (3) Ratio } \\
\text { (1)/(2) }\end{array}$} & \multicolumn{2}{|c|}{$\begin{array}{l}\text { (4) DRG } 134 \\
\text { Hypertension }\end{array}$} \\
\hline & Tariff & $\begin{array}{l}\text { as \% of } \\
\text { national }\end{array}$ & Tariff & $\begin{array}{l}\text { as \% of } \\
\text { national }\end{array}$ & & Tariff & $\begin{array}{l}\text { as \% of } \\
\text { national }\end{array}$ \\
\hline National & 1489.46 & & 2359.69 & & 1.58 & 2015.73 & \\
\hline Lombardia & 1648.00 & 1.10 & 1718.00 & 0.73 & 1.04 & 1525.00 & 0.76 \\
\hline Veneto & 836.66 & 0.56 & 1992.49 & 0.84 & 2.38 & 1057.19 & 0.52 \\
\hline Emilia Romag. & 697.22 & 0.47 & 1389.27 & 0.59 & 1.99 & 1549.37 & 0.77 \\
\hline Toscana & 1185.42 & 0.80 & 2659.89 & 1.13 & 2.24 & 1689.86 & 0.84 \\
\hline Umbria & 1750.00 & 1.17 & 2864.00 & 1.21 & 1.64 & 2144.00 & 1.06 \\
\hline
\end{tabular}

Source: ASSR (2003). Note: all tariffs in Euros 2002. Selected DRGs include the most common one for the share of hospital admissions (DRG 373; 3.53\% of all admissions) and the closest alternative (DRG 371; $1.75 \%$ ), plus the most common among those at risk of organizational inappropriateness (DRG 134; $0.91 \%$ ). 


\begin{tabular}{lcccccc}
\hline & $\begin{array}{c}(1) \\
\text { Total }\end{array}$ & $\begin{array}{c}(2) \\
\text { Not exposed to } \\
\text { treatment }\end{array}$ & $\begin{array}{c}(3) \\
\text { Exposed to } \\
\text { treatment }\end{array}$ & $\begin{array}{c}(4) \\
<1997\end{array}$ & $\begin{array}{c}(5) \\
1997-1999\end{array}$ & $\begin{array}{c}(6) \\
\text { Good health }\end{array}$ \\
\cline { 2 - 7 } & 0.72 & 0.73 & 0.71 & 0.72 & 0.73 & 0.72 \\
ER (y/n) & 0.08 & 0.09 & 0.07 & 0.12 & 0.06 & 0.07 \\
Day Hospital (y/n) & 0.03 & 0.03 & 0.03 & 0.03 & 0.02 & \\
Hospitalization (y/n) & 0.05 & 0.06 & 0.04 & 0.09 & 0.04 & 0.04 \\
Sat docs if hosp (1-4) & 3.24 & 3.21 & 3.31 & 3.24 & 3.22 & 3.24 \\
Fully satisf by docs if hosp & 0.36 & 0.34 & 0.42 & 0.36 & 0.36 & 0.36 \\
ALE & 79.5 & 79.2 & 80.5 & 78.1 & 78.9 & 80.6 \\
IMR & 47.1 & 50.6 & 35.8 & 61.5 & 51.3 & 37.1 \\
Private insurance ownership & 0.25 & 0.23 & 0.3 & 0.23 & 0.24 & 0.26 \\
Treatment & 0.35 & & & 0.00 & 0.36 & 0.55 \\
\hline
\end{tabular}

Note: Satisfaction of the service provided by the doctors (in case of hospitalization) is coded as a binary indicator equal to 1 if the individual reported a value of 4 , on a 1 to 4 rating scale. The 'treatment' category identifies treated regions, in the post-adoption period. 


\begin{tabular}{lccccc}
\hline & $(1)$ & $(2)$ & $(3)$ & $(4)$ & $(5)$ \\
& SAH & ER & Day Hospital & Hospitalization & Sat. if hospitalized \\
\cline { 2 - 5 } & \multicolumn{5}{c}{ Panel A: Full sample } \\
\hline $\mathrm{t}=\tau(\mathrm{r})-2$ & -0.006 & 0.005 & 0.003 & -0.003 \\
& $(0.148)$ & $(0.362)$ & $(0.506)$ & $(1)$ \\
$\mathrm{t}=\tau(\mathrm{r})-1$ & $-0.009^{* *}$ & -0.001 & -0.000 & 0.015 \\
& $(0.016)$ & $(0.866)$ & $(0.91)$ & $(0.628)$ \\
$\mathrm{t}=\tau(\mathrm{r})$ & -0.012 & -0.008 & -0.002 & 0.013 \\
& $(0.124)$ & $(0.278)$ & $(0.692)$ & $(0.728)$ \\
$\mathrm{t}=\tau(\mathrm{r})+1$ & -0.008 & -0.008 & 0.001 & -0.012 \\
& $(0.276)$ & $(0.334)$ & $(0.918$ & $(0.68)$ \\
$\mathrm{t} \geq \tau(\mathrm{r})+2$ & -0.002 & $-0.020^{* *}$ & -0.005 & $-0.040^{*}$ \\
& $(0.804)$ & $(0.028)$ & $(0.352)$ & $(0.106)$ \\
Observations & 660,326 & 663,894 & & \\
Adj-R2 & 0.271 & 0.016 & 665,660 & 34,726 \\
& & & 0.032 & 0.069
\end{tabular}

Panel B: Excluding late adopters (Piedmont, Lazio and Sicily)

\begin{tabular}{lcccc}
\hline $\mathrm{t}=\tau(\mathrm{r})-2$ & -0.005 & -0.004 & -0.006 & -0.022 \\
& $(0.322)$ & $(0.842)$ & $(0.354)$ & $(0.72)$ \\
$\mathrm{t}=\tau(\mathrm{r})-1$ & -0.004 & -0.017 & -0.010 & -0.014 \\
& $(0.648)$ & $(0.368)$ & $(0.146)$ & $(0.59)$ \\
$\mathrm{t}=\tau(\mathrm{r})$ & -0.002 & $-0.037 * * *$ & -0.013 & -0.027 \\
& $(0.876)$ & $(0.002)$ & $(0.232)$ & $(0.592)$ \\
$\mathrm{t}=\tau(\mathrm{r})+1$ & 0.000 & $-0.038^{* * *}$ & -0.011 & -0.026 \\
& $(0.976)$ & $(0.006)$ & $(0.18)$ & $(0.31)$ \\
$\mathrm{t} \geq \tau(\mathrm{r})+2$ & -0.002 & $-0.039^{* * *}$ & -0.014 & $-0.056^{* *}$ \\
& $(0.85)$ & $(0.008)$ & $(0.128)$ & $(0.044)$ \\
& & & & \\
Observations & 523,412 & 525,874 & 527,273 & 28,016 \\
Adj-R2 & 0.265 & 0.018 & 0.033 & 0.068
\end{tabular}

Panel C: Time window with full support from central government (1993-1999)

\begin{tabular}{lccccc}
\hline $\mathrm{t}=\tau(\mathrm{r})-2$ & $-0.008^{*}$ & 0.004 & 0.002 & -0.003 & -0.025 \\
& $(0.108)$ & $(0.75)$ & $(0.534)$ & $(0.53)$ & $(0.774)$ \\
$\mathrm{t}=\tau(\mathrm{r})-1$ & -0.005 & -0.010 & 0.000 & $-0.011^{* *}$ & -0.004 \\
& $(0.43)$ & $(0.678)$ & $(0.924)$ & $(0.016)$ & $(0.892)$ \\
$\mathrm{t}=\tau(\mathrm{r})$ & 0.000 & $-0.031 * * *$ & -0.002 & $-0.015 * *$ & -0.028 \\
& $(0.968)$ & $(0.002)$ & $(0.228)$ & $(0.048)$ & $(0.598)$ \\
$\mathrm{t}=\tau(\mathrm{r})+1$ & 0.008 & $-0.032 * * *$ & -0.002 & $-0.010^{* *}$ & -0.022 \\
& $(0.278)$ & $(0.002)$ & $(0.612)$ & $(0.038)$ & $(0.188)$ \\
$\mathrm{t} \geq \tau(\mathrm{r})+2$ & $0.019 * *$ & $-0.034 * *$ & -0.004 & $-0.012 * *$ & -0.064 \\
& $(0.044)$ & $(0.012)$ & $(0.566)$ & $(0.042)$ & $(0.174)$ \\
& & & \\
Observations & 354,296 & 355,610 & 351,700 & 357,134 & 23,576 \\
Adj-R2 & 0.273 & 0.021 & 0.005 & 0.034 & 0.071 \\
\hline & All models control for age and its square, gender and educational level, plus region and year fixed effects. \\
$\tau(\mathrm{r})$ is the year of DRG adoption in region r, the reference category for treatment dummies is $\mathrm{t} \leq \tau(\mathrm{r})-3$. \\
Robust p-values in parentheses account for clustering at the region level and are obtained by wild bootstrap \\
using 1000 repetitions. ***, ** and * for statistical significance at the 1, 5 and 10 percent confidence level.
\end{tabular}


Table 4: Estimates with region specific trend and longer term effects

\begin{tabular}{|c|c|c|c|c|c|}
\hline & $\begin{array}{c}(1) \\
\text { SAH }\end{array}$ & $\begin{array}{l}(2) \\
\text { ER }\end{array}$ & $\begin{array}{c}\text { (3) } \\
\text { Day Hospital }\end{array}$ & $\begin{array}{c}\text { (4) } \\
\text { Hospitalization }\end{array}$ & $\begin{array}{c}(5) \\
\text { Sat. if hospitalized }\end{array}$ \\
\hline \multicolumn{6}{|c|}{ Panel A: Including region-specific trends } \\
\hline $\mathrm{t}=\tau(\mathrm{r})-2$ & $\begin{array}{c}0.001 \\
(0.746)\end{array}$ & $\begin{array}{c}0.000 \\
(0.968)\end{array}$ & $\begin{array}{l}-0.003 \\
(0.78)\end{array}$ & $\begin{array}{l}-0.002 \\
(0.606)\end{array}$ & $\begin{array}{l}-0.005 \\
(0.962)\end{array}$ \\
\hline $\mathrm{t}=\tau(\mathrm{r})-1$ & $\begin{array}{l}-0.001 \\
(0.71)\end{array}$ & $\begin{array}{l}-0.006 \\
(0.542)\end{array}$ & $\begin{array}{l}-0.009 \\
(0.602)\end{array}$ & $\begin{array}{c}-0.005 * * \\
(0.036)\end{array}$ & $\begin{array}{l}0.012 \\
(0.71)\end{array}$ \\
\hline $\mathrm{t}=\tau(\mathrm{r})$ & $\begin{array}{l}-0.003 \\
(0.59)\end{array}$ & $\begin{array}{l}-0.013 \\
(0.142)\end{array}$ & $\begin{array}{l}-0.015 \\
(0.496)\end{array}$ & $\begin{array}{l}-0.007 * \\
(0.098)\end{array}$ & $\begin{array}{c}0.008 \\
(0.852)\end{array}$ \\
\hline $\mathrm{t}=\tau(\mathrm{r})+1$ & $\begin{array}{l}0.002 \\
(0.68)\end{array}$ & $\begin{array}{l}-0.013 \\
(0.18)\end{array}$ & $\begin{array}{l}-0.018 \\
(0.558)\end{array}$ & $\begin{array}{c}-0.005 * * \\
(0.036)\end{array}$ & $\begin{array}{l}-0.017 \\
(0.692)\end{array}$ \\
\hline$t \geq \tau(r)+2$ & $\begin{array}{c}0.009 \\
(0.118)\end{array}$ & $\begin{array}{c}-0.022 * * \\
(0.014)\end{array}$ & $\begin{array}{l}-0.025 \\
(0.476)\end{array}$ & $\begin{array}{c}-0.009 * * * \\
(0.002)\end{array}$ & $\begin{array}{l}-0.049 \\
(0.322)\end{array}$ \\
\hline $\begin{array}{l}\text { Observations } \\
\text { Adj-R2 }\end{array}$ & $\begin{array}{c}660,326 \\
0.271\end{array}$ & $\begin{array}{c}663,894 \\
0.016\end{array}$ & $\begin{array}{c}351,700 \\
0.005\end{array}$ & $\begin{array}{c}665,660 \\
0.032\end{array}$ & $\begin{array}{c}34,726 \\
0.069\end{array}$ \\
\hline \multicolumn{6}{|c|}{ Panel B: Longer term treatment effects } \\
\hline $\mathrm{t}=\tau(\mathrm{r})-2$ & $\begin{array}{l}-0.005 \\
(0.324)\end{array}$ & $\begin{array}{l}-0.004 \\
(0.842)\end{array}$ & & $\begin{array}{l}-0.006 \\
(0.354)\end{array}$ & $\begin{array}{l}-0.022 \\
(0.72)\end{array}$ \\
\hline $\mathrm{t}=\tau(\mathrm{r})-1$ & $\begin{array}{l}-0.004 \\
(0.648)\end{array}$ & $\begin{array}{l}-0.017 \\
(0.366)\end{array}$ & & $\begin{array}{l}-0.010 \\
(0.146)\end{array}$ & $\begin{array}{l}-0.014 \\
(0.59)\end{array}$ \\
\hline$t=\tau(r)$ & $\begin{array}{l}-0.002 \\
(0.878)\end{array}$ & $\begin{array}{c}-0.037 * * * \\
(0.002)\end{array}$ & & $\begin{array}{l}-0.013 \\
(0.236)\end{array}$ & $\begin{array}{l}-0.027 \\
(0.58)\end{array}$ \\
\hline $\mathrm{t}=\tau(\mathrm{r})+1$ & $\begin{array}{c}0.000 \\
(0.976)\end{array}$ & $\begin{array}{c}-0.038 * * * \\
(0.006)\end{array}$ & & $\begin{array}{l}-0.011 \\
(0.186)\end{array}$ & $\begin{array}{l}-0.031 \\
(0.262)\end{array}$ \\
\hline$t=\tau(r)+2$ & $\begin{array}{l}-0.001 \\
(0.916)\end{array}$ & $\begin{array}{c}-0.043 * * \\
(0.014)\end{array}$ & & $\begin{array}{l}-0.014 \\
(0.164)\end{array}$ & $\begin{array}{c}-0.090 * * \\
(0.032)\end{array}$ \\
\hline$t=\tau(r)+3$ & $\begin{array}{l}-0.004 \\
(0.504)\end{array}$ & $\begin{array}{c}-0.040 * * * \\
(0.004)\end{array}$ & & $\begin{aligned}-0.017 * \\
(0.062)\end{aligned}$ & $\begin{array}{l}-0.017 \\
(0.586)\end{array}$ \\
\hline $\mathrm{t}=\tau(\mathrm{r})+4$ & $\begin{array}{l}-0.003 \\
(0.788)\end{array}$ & $\begin{array}{c}-0.045^{* * *} \\
(0.004)\end{array}$ & & $\begin{array}{c}-0.017 * \\
(0.09)\end{array}$ & $\begin{array}{c}-0.120 * * * \\
(0.004)\end{array}$ \\
\hline $\mathrm{t}=\tau(\mathrm{r})+5$ & $\begin{array}{l}-0.001 \\
(0.928)\end{array}$ & $\begin{array}{c}-0.038 * * * \\
(0.008)\end{array}$ & & $\begin{array}{l}-0.016 \\
(0.116)\end{array}$ & $\begin{array}{l}-0.006 \\
(0.908)\end{array}$ \\
\hline$t \geq \tau(r)+6$ & $\begin{array}{l}-0.001 \\
(0.874)\end{array}$ & $\begin{array}{c}-0.035^{* * *} \\
(0.01)\end{array}$ & & $\begin{array}{l}-0.013 \\
(0.174)\end{array}$ & $\begin{array}{c}-0.050 * * \\
(0.068)\end{array}$ \\
\hline $\begin{array}{l}\text { Observations } \\
\text { Adj-R2 }\end{array}$ & $\begin{array}{c}523,412 \\
0.265\end{array}$ & $\begin{array}{c}525,874 \\
0.018\end{array}$ & & $\begin{array}{c}527,273 \\
0.033\end{array}$ & $\begin{array}{c}28,016 \\
0.069\end{array}$ \\
\hline
\end{tabular}

All models control for age and its square, gender and educational level, plus region and year fixed effects. $\tau(\mathrm{r})$ is the year of DRG adoption in region $\mathrm{r}$, the reference category for treatment dummies is $t \leq \tau(r)-3$. Robust p-values in parentheses account for clustering at the region level and are obtained by wild bootstrap using 1000 repetitions. Estimates in Panel A, Column 3 are derived from the 1993-1999 sample. Estimates in Panel B are derived from the sample that excludes Piedmont, Lazio and Sicily. $* * *, * *$ and $*$ for statistical significance at the 1,5 and 10 percent confidence level. 
Table 5: Regional-level regressions including objective health measures as outcomes

\begin{tabular}{lcccccc}
\hline & $(1)$ & $(2)$ & $(3)$ & $(4)$ & $(5)$ & $(6)$ \\
& SAH & ER & Day Hospital & Hospitalization & ALE & IMR \\
\cline { 2 - 7 } & \multicolumn{7}{c}{ Panel A: Region fixed effects } \\
\hline $\mathrm{t}=\mathrm{t}(\mathrm{r})-2$ & -0.005 & 0.003 & 0.003 & 0.003 & 0.006 & 0.343 \\
& $(0.418)$ & $(0.555)$ & $(0.357)$ & $(0.298)$ & $(0.910)$ & $(0.896)$ \\
$\mathrm{t}=\mathrm{t}(\mathrm{r})-1$ & -0.008 & -0.003 & 0.002 & 0.002 & -0.002 & -1.668 \\
& $(0.232)$ & $(0.701)$ & $(0.452)$ & $(0.511)$ & $(0.975)$ & $(0.452)$ \\
$\mathrm{t}=\mathrm{t}(\mathrm{r})$ & -0.008 & $-0.009 *$ & -0.001 & 0.001 & 0.032 & 1.309 \\
& $(0.291)$ & $(0.092)$ & $(0.743)$ & $(0.866)$ & $(0.486)$ & $(0.559)$ \\
$\mathrm{t}=\mathrm{t}(\mathrm{r})+1$ & -0.009 & -0.009 & -0.003 & 0.002 & 0.007 & 1.237 \\
& $(0.207)$ & $(0.133)$ & $(0.375)$ & $(0.430)$ & $(0.881)$ & $(0.533)$ \\
$\mathrm{t} \geq \mathrm{t}(\mathrm{r})+2$ & 0.001 & $-0.018^{*} * *$ & -0.005 & -0.002 & $0.157 * * *$ & 1.533 \\
& $(0.825)$ & $(0.000)$ & $(0.194)$ & $(0.553)$ & $(0.001)$ & $(0.478)$ \\
& & & & & \\
Observations & 266 & 266 & 133 & 266 & 266 & 266 \\
Adj-R2 & 0.680 & 0.853 & 0.621 & 0.940 & 0.991 & 0.824
\end{tabular}

Panel B: Region fixed effects and trends

\begin{tabular}{lcccccc}
\hline $\mathrm{t}=\mathrm{t}(\mathrm{r})-2$ & 0.003 & -0.002 & -0.006 & -0.002 & -0.003 & -0.779 \\
& $(0.567)$ & $(0.692)$ & $(0.313)$ & $(0.465)$ & $(0.935)$ & $(0.734)$ \\
$\mathrm{t}=\mathrm{t}(\mathrm{r})-1$ & 0.001 & -0.008 & -0.013 & $-0.004^{*}$ & -0.014 & -2.784 \\
& $(0.939)$ & $(0.244)$ & $(0.133)$ & $(0.093)$ & $(0.756)$ & $(0.154)$ \\
$\mathrm{t}=\mathrm{t}(\mathrm{r})$ & 0.001 & $-0.015 * * *$ & $-0.022^{*}$ & $-0.006^{*}$ & 0.015 & -0.864 \\
& $(0.870)$ & $(0.007)$ & $(0.057)$ & $(0.071)$ & $(0.739)$ & $(0.692)$ \\
$\mathrm{t}=\mathrm{t}(\mathrm{r})+1$ & 0.001 & $-0.015^{* * *}$ & $-0.030^{* *}$ & $-0.005^{* *}$ & -0.014 & -1.534 \\
& $(0.896)$ & $(0.008)$ & $(0.043)$ & $(0.027)$ & $(0.790)$ & $(0.422)$ \\
$\mathrm{t} \geq \mathrm{t}(\mathrm{r})+2$ & 0.010 & $-0.022^{* * *}$ & $-0.039 * *$ & $-0.010^{* * *}$ & $0.111 * *$ & -4.029 \\
& $(0.250)$ & $(0.000)$ & $(0.036)$ & $(0.001)$ & $(0.046)$ & $(0.117)$ \\
& & & & & & \\
Observations & 266 & 266 & 133 & 266 & 266 & 266 \\
Adj-R2 & 0.756 & 0.902 & 0.697 & 0.957 & 0.994 & 0.871 \\
\hline
\end{tabular}

All models control for age and its square, gender and educational level, plus region and year fixed effects. $\tau(\mathrm{r})$ is the year of DRG adoption in region $r$, the reference category for treatment dummies is $t \leq \tau(r)-3$. P-values in parentheses. Estimates in Column 3 are derived from the 1993-1999 sample. Outcomes in Columns (5) and (6) are derived from the ISTAT Health for All Survey. ***, ** and * for statistical significance at the 1,5 and 10 percent confidence level. 
(1)

Region fixed effects
(2)

Region fixed effects and trends

\begin{tabular}{lcc}
$\mathrm{t}=\tau(\mathrm{r})-2$ & 0.01 & 0.013 \\
& $(0.278)$ & $(.114)$ \\
$\mathrm{t}=\tau(\mathrm{r})-1$ & 0.015 & $0.017^{*}$ \\
& $(0.072)$ & $(.064)$ \\
$\mathrm{t}=\tau(\mathrm{r})$ & 0.005 & 0.008 \\
& $(0.422)$ & $(0.324)$ \\
$\mathrm{t}=\tau(\mathrm{r})+1$ & $0.016^{* *}$ & $0.019^{* *}$ \\
& $(0.042)$ & $(0.048)$ \\
$\mathrm{t} \geq \tau(\mathrm{r})+2$ & $0.015^{* *}$ & 0.014 \\
& $(.046)$ & $(0.148)$ \\
& & \\
Observations & 293,598 & 293,598 \\
Adj-R2 & 0.123 & 0.123 \\
\hline
\end{tabular}

Regression are run at the household level controlling for individual characteristics of the head (age and its square, gender and educational level), plus region and year fixed effects. $\tau(\mathrm{r})$ is the year of DRG adoption in region $r$, the reference category for treatment dummies is $t \leq \tau(r)-3$. Region and year fixed effects are also included. Robust p-values in parentheses account for clustering at the region level and are obtained by wild bootstrap using 1000 repetitions. ***, ** and * for statistical significance at the 1 , 5 and 10 percent confidence level. 
Table 7: Heterogeneous effects by birth cohort

\begin{tabular}{|c|c|c|c|c|c|}
\hline & $\begin{array}{l}(1) \\
\text { SAH } \\
\end{array}$ & $\begin{array}{l}(2) \\
\text { ER }\end{array}$ & $\begin{array}{c}\text { (3) } \\
\text { Day Hospital } \\
\end{array}$ & $\begin{array}{c}\text { (4) } \\
\text { Hospitalization } \\
\end{array}$ & $\begin{array}{c}(5) \\
\text { Sat. if hospitalized }\end{array}$ \\
\hline $\mathrm{t}=\tau(\mathrm{r})-2$ & $\begin{array}{l}-0.006 \\
(0.208)\end{array}$ & $\begin{array}{c}0.008 * * \\
(0.046)\end{array}$ & $\begin{array}{l}-0.002 \\
(0.486)\end{array}$ & $\begin{array}{c}0.001 \\
(0.904)\end{array}$ & $\begin{array}{l}-0.051 \\
(0.406)\end{array}$ \\
\hline $\mathrm{t}=\tau(\mathrm{r})-1$ & $\begin{array}{l}-0.012 \\
(0.174)\end{array}$ & $\begin{array}{c}0.003 \\
(0.818)\end{array}$ & $\begin{array}{l}-0.001 \\
(0.778)\end{array}$ & $\begin{array}{c}0.003 \\
(0.544)\end{array}$ & $\begin{array}{c}0.012 \\
(0.848)\end{array}$ \\
\hline $\mathrm{t}=\tau(\mathrm{r})$ & $\begin{array}{c}-0.015 * * \\
(0.024)\end{array}$ & $\begin{array}{l}-0.009 \\
(0.108)\end{array}$ & $\begin{array}{l}-0.002 \\
(0.572)\end{array}$ & $\begin{array}{c}0.002 \\
(0.638)\end{array}$ & $\begin{array}{l}-0.014 \\
(0.852)\end{array}$ \\
\hline $\mathrm{t}=\tau(\mathrm{r})+1$ & $\begin{array}{c}-0.010 * * \\
(0.036)\end{array}$ & $\begin{array}{l}-0.009 \\
(0.206)\end{array}$ & $\begin{array}{l}-0.003 \\
(0.536)\end{array}$ & $\begin{array}{c}0.006 \\
(0.182)\end{array}$ & $\begin{array}{l}-0.054 \\
(0.17)\end{array}$ \\
\hline $\mathrm{t} \geq \tau(\mathrm{r})+2$ & $\begin{array}{l}-0.012 \\
(0.204)\end{array}$ & $\begin{array}{c}-0.022 * * \\
(0.024)\end{array}$ & $\begin{array}{l}-0.004 \\
(0.582)\end{array}$ & $\begin{array}{c}0.003 \\
(0.694)\end{array}$ & $\begin{array}{l}-0.065^{*} \\
(0.072)\end{array}$ \\
\hline before $48^{*} \mathrm{t}=\tau(\mathrm{r})-2$ & $\begin{array}{c}-0.000 \\
(1)\end{array}$ & $\begin{array}{l}-0.007 \\
(0.346)\end{array}$ & $\begin{array}{c}0.008 \\
(0.132)\end{array}$ & $\begin{array}{c}0.004 \\
(0.718)\end{array}$ & $\begin{array}{c}0.074 * \\
(0.09)\end{array}$ \\
\hline before $48^{*} \mathrm{t}=\tau(\mathrm{r})-1$ & $\begin{array}{c}0.006 \\
(0.586)\end{array}$ & $\begin{array}{l}-0.009 \\
(0.628)\end{array}$ & $\begin{array}{c}0.002 \\
(0.584)\end{array}$ & $\begin{array}{l}-0.008 \\
(0.164)\end{array}$ & $\begin{array}{l}0.003 \\
(0.87)\end{array}$ \\
\hline before $48 * \mathrm{t}=\tau(\mathrm{r})$ & $\begin{array}{c}0.006 \\
(0.578)\end{array}$ & $\begin{array}{l}0.002 \\
(0.72)\end{array}$ & $\begin{array}{c}0.001 \\
(0.942)\end{array}$ & $\begin{array}{c}-0.009^{*} \\
(0.14)\end{array}$ & $\begin{array}{c}0.038 \\
(0.574)\end{array}$ \\
\hline before $48^{*} \mathrm{t}=\tau(\mathrm{r})+1$ & $\begin{array}{c}0.005 \\
(0.692)\end{array}$ & $\begin{array}{c}0.003 \\
(0.694)\end{array}$ & $\begin{array}{c}0.002 \\
(0.658)\end{array}$ & $\begin{array}{c}-0.013 * * * \\
(0.004)\end{array}$ & $\begin{array}{c}0.065 \\
(0.204)\end{array}$ \\
\hline before $48 * t \geq \tau(r)+2$ & $\begin{array}{c}0.020 * * \\
(0.02)\end{array}$ & $\begin{array}{l}0.005 \\
(0.18)\end{array}$ & $\begin{array}{c}0.001 \\
(0.866)\end{array}$ & $\begin{array}{c}-0.019 * * * \\
(0.002)\end{array}$ & $\begin{array}{l}0.040^{*} \\
(0.07)\end{array}$ \\
\hline $\begin{array}{l}\text { Observations } \\
\text { Adj-R2 }\end{array}$ & $\begin{array}{c}660,326 \\
0.268\end{array}$ & $\begin{array}{c}663,894 \\
0.016\end{array}$ & $\begin{array}{c}351,700 \\
0.005\end{array}$ & $\begin{array}{c}665,660 \\
0.032\end{array}$ & $\begin{array}{c}34,726 \\
0.069\end{array}$ \\
\hline
\end{tabular}

All models control for age and its square, gender and educational level, plus region and year fixed effects. $\tau(r)$ is the year of DRG adoption in region $r$, the reference category for treatment dummies is $t \leq \tau(r)-3$. Robust p-values in parentheses account for clustering at the region level and are obtained by wild bootstrap using 1000 repetitions. Before 48 is a dummy variable for those born before 1948 . ***,** and $*$ for statistical significance at the 1,5 and 10 percent confidence level. 
Table 8: Heterogeneous effects by educational attainment

\begin{tabular}{lccccc}
\hline & $(1)$ & $(2)$ & $(3)$ & $(3)$ & $(4)$ \\
& SAH & ER & Day Hospital & Hospitalization & Sat. if hospitalized \\
\cline { 2 - 6 } & \multicolumn{5}{c}{ Panel A: Compulsory education } \\
$\mathrm{n}=\tau(\mathrm{r})-2$ & -0.008 & 0.006 & -0.001 & 0.004 & -0.002 \\
$\mathrm{t}=\tau(\mathrm{r})-1$ & $(0.304)$ & $(0.374)$ & $(0.738)$ & $(0.504)$ & $(0.904)$ \\
& -0.007 & -0.001 & $-0.005^{*}$ & 0.004 & 0.015 \\
$\mathrm{t}=\tau(\mathrm{r})$ & $(0.18)$ & $(0.94)$ & $(0.098)$ & $(0.548)$ & $(0.566)$ \\
& -0.012 & -0.005 & -0.001 & 0.002 & 0.013 \\
$\mathrm{t}=\tau(\mathrm{r})+1$ & $(0.228)$ & $(0.492)$ & $(0.656)$ & $(0.708)$ & $(0.71)$ \\
& -0.016 & -0.005 & -0.002 & 0.000 & -0.009 \\
$\mathrm{t} \geq \tau(\mathrm{r})+2$ & $(0.14)$ & $(0.638)$ & $(0.594)$ & $(0.926)$ & $(0.59)$ \\
& -0.002 & $-0.017 *$ & -0.005 & -0.004 & -0.037 \\
& $(0.754)$ & $(0.07)$ & $(0.552)$ & $(0.586)$ & $(0.116)$ \\
Observations & & & & & \\
Adj-R2 & 405,330 & 407,553 & 221,757 & 408,822 & 25,515 \\
& 0.253 & 0.014 & 0.004 & 0.032 & 0.069
\end{tabular}

Panel B: Upper secondary education

$\begin{array}{lccccc}\mathrm{t}=\tau(\mathrm{r})-2 & 0.002 & 0.006 & 0.005 & 0.002 & -0.022 \\ & (0.698) & (0.604) & (0.372) & (0.722) & (0.592) \\ \mathrm{t}=\tau(\mathrm{r})-1 & -0.010 & -0.002 & 0.008^{* *} & -0.009 * * & 0.022 \\ & (0.138) & (0.856) & (0.048) & (0.016) & (0.758) \\ \mathrm{t}=\tau(\mathrm{r}) & -0.009 & -0.012 & -0.001 & -0.011^{* *} & -0.046 \\ & (0.348) & (0.178) & (0.806) & (0.032) & (0.62) \\ \mathrm{t}=\tau(\mathrm{r})+1 & 0.005 & -0.013 & -0.001 & 0.003 & -0.003 \\ & (0.334) & (0.222) & (0.788) & (0.37) & (0.99) \\ \mathrm{t} \geq \tau(\mathrm{r})+2 & 0.001 & -0.025^{* *} & -0.002 & -0.009 * & -0.045 \\ & (0.84) & (0.02) & (0.666) & (0.088) & (0.262) \\ & & & & & \\ \text { Observations } & 206,355 & 207,374 & 106,961 & 207,796 & 7,529 \\ \text { Adj-R2 } & 0.125 & 0.016 & 0.005 & 0.018 & 0.056\end{array}$

Panel C: Tertiary education

\begin{tabular}{lccccc}
\hline $\mathrm{t}=\tau(\mathrm{r})-2$ & $-0.029 * * *$ & -0.000 & 0.022 & -0.002 & -0.021 \\
& $(0.002)$ & $(0.996)$ & $(0.364)$ & $(0.9)$ & $(0.742)$ \\
$\mathrm{t}=\tau(\mathrm{r})-1$ & -0.022 & 0.003 & 0.013 & 0.003 & -0.040 \\
& $(0.316)$ & $(0.744)$ & $(0.408)$ & $(0.636)$ & $(0.792)$ \\
$\mathrm{t}=\tau(\mathrm{r})$ & -0.021 & -0.015 & -0.008 & 0.001 & $0.110^{*}$ \\
& $(0.336)$ & $(0.282)$ & $(0.324)$ & $(0.828)$ & $(0.086)$ \\
$\mathrm{t}=\tau(\mathrm{r})+1$ & 0.004 & $-0.015^{*}$ & 0.001 & -0.004 & -0.095 \\
& $(0.762)$ & $(0.108)$ & $(0.866)$ & $(0.328)$ & $(0.558)$ \\
$\mathrm{t} \geq \tau(\mathrm{r})+2$ & -0.007 & $-0.027^{* *}$ & -0.002 & -0.004 & -0.097 \\
& $(0.608)$ & $(0.02)$ & $(0.834)$ & $(0.234)$ & $(0.192)$ \\
Observations & & & & & \\
Adj-R2 & 48,641 & 48,967 & 22,982 & 49,042 & 1,682 \\
\hline All & 0.115 & 0.013 & 0.011 & 0.023 & 0.095 \\
\hline
\end{tabular}

All models control for age and its square, gender and educational level, plus region and year fixed effects. $\tau(\mathrm{r})$ is the year of DRG adoption in region $r$, the reference category for treatment dummies is $t \leq \tau(r)-3$. Robust $p$-values in parentheses account for clustering at the region level and are obtained by wild bootstrap using 1000 repetitions. Estimates in Column 3 are derived from the 1993-1999 sample. ***, ** and * for statistical significance at the 1, 5 and 10 percent confidence level. 


\begin{tabular}{ccccc}
$(1)$ & $(2)$ & $(3)$ & $(4)$ & $(5)$ \\
$\mathrm{t}=\tau(\mathrm{r})-2$ & $\mathrm{t}=\tau(\mathrm{r})-1$ & $\mathrm{t}=\tau(\mathrm{r})$ & $\mathrm{t}=\tau(\mathrm{r})+1$ & $\mathrm{t} \geq \tau(\mathrm{r})+2$ \\
\hline
\end{tabular}

Panel A: SAH (Observations=660,326; Adj-R2=0.271)

\begin{tabular}{|c|c|c|c|c|c|}
\hline Piedmont & $\begin{array}{c}0.009 \\
(0.624)\end{array}$ & $\begin{array}{l}-0.015 \\
(0.422)\end{array}$ & $\begin{array}{l}-0.009 \\
(0.362)\end{array}$ & $\begin{array}{l}0.003 \\
(.768)\end{array}$ & $\begin{array}{l}0.006 \\
(.402)\end{array}$ \\
\hline Lombardy & $\begin{array}{l}-0.007 \\
(0.284)\end{array}$ & $\begin{array}{c}0.005 \\
(0.594)\end{array}$ & $\begin{array}{c}0.014 * * * \\
(0.000)\end{array}$ & $\begin{array}{c}0.014 * * \\
(.032)\end{array}$ & $\begin{array}{c}0.015 * * * \\
(.008)\end{array}$ \\
\hline Veneto & $\begin{array}{l}-0.004 \\
(0.55)\end{array}$ & $\begin{array}{l}-0.013 \\
(0.214)\end{array}$ & $\begin{array}{c}-0.009 * * \\
(0.042)\end{array}$ & $\begin{array}{l}0.007 \\
(.69)\end{array}$ & $\begin{array}{c}-0.017 * * * \\
(.002)\end{array}$ \\
\hline Emilia-Romagna & $\begin{array}{l}-0.016 \\
(0.286)\end{array}$ & $\begin{array}{l}-0.019 \\
(0.452)\end{array}$ & $\begin{array}{c}-0.042 * * * \\
(0.002)\end{array}$ & $\begin{array}{c}0.002 \\
(1)\end{array}$ & $\begin{array}{c}-0.008 * * * \\
(.006)\end{array}$ \\
\hline Tuscany & $\begin{array}{l}-0.010 \\
(0.294)\end{array}$ & $\begin{array}{c}-0.004 \\
(0.598)\end{array}$ & $\begin{array}{l}0.013 * \\
(0.064)\end{array}$ & $\begin{array}{c}-0.009 * * \\
(.036)\end{array}$ & $\begin{array}{l}0.007 \\
(.652)\end{array}$ \\
\hline Umbria & $\begin{array}{c}0.027 \\
(0.688)\end{array}$ & $\begin{array}{c}0.010 \\
(0.556)\end{array}$ & $\begin{array}{c}0.060 * * * \\
(0.000)\end{array}$ & $\begin{array}{c}0.020 * * * \\
(0.000)\end{array}$ & $\begin{array}{c}0.034 * * * \\
(0.000)\end{array}$ \\
\hline Lazio & $\begin{array}{c}0.011 \\
(0.462)\end{array}$ & & $\begin{array}{c}-0.020 * * \\
(0.01)\end{array}$ & $\begin{array}{c}-0.035^{* * * *} \\
(.002)\end{array}$ & $\begin{array}{l}0.001 \\
(.694)\end{array}$ \\
\hline Sicily & $\begin{array}{l}-0.021 \\
(0.44)\end{array}$ & $\begin{array}{c}0.004 \\
(0.694)\end{array}$ & $\begin{array}{c}-0.035^{* * * *} \\
(0.002)\end{array}$ & $\begin{array}{c}-0.019 * * * \\
(.004)\end{array}$ & $\begin{array}{c}-0.021 * * \\
(.002)\end{array}$ \\
\hline \multicolumn{6}{|c|}{ Panel B: ER (Observations=663,894; Adj-R2=0.016) } \\
\hline Piedmont & $\begin{array}{c}-0.008 \\
(0.34)\end{array}$ & $\begin{array}{l}-0.011 \\
(0.36)\end{array}$ & $\begin{array}{c}0.003 \\
(0.608)\end{array}$ & $\begin{array}{c}-0.007 * * * \\
(0.006)\end{array}$ & $\begin{array}{c}-0.015 * * * \\
(0.002)\end{array}$ \\
\hline Lombardy & $\begin{array}{c}0.014 \\
(0.278)\end{array}$ & $\begin{array}{l}-0.002 \\
(0.622)\end{array}$ & $\begin{array}{c}-0.038 * * * \\
(0.002)\end{array}$ & $\begin{array}{c}-0.023 * * * \\
(0.002)\end{array}$ & $\begin{array}{c}-0.031 * * * \\
(0.004)\end{array}$ \\
\hline Veneto & $\begin{array}{l}-0.009 \\
(0.418)\end{array}$ & $\begin{array}{l}-0.056 \\
(0.168)\end{array}$ & $\begin{array}{c}-0.034 * * * \\
(0.002)\end{array}$ & $\begin{array}{c}-0.051 * * * \\
(0.002)\end{array}$ & $\begin{array}{c}-0.051 * * * \\
(0.002)\end{array}$ \\
\hline Emilia-Romagna & $\begin{array}{l}0.009 \\
(0.28)\end{array}$ & $\begin{array}{l}0.019 \\
(0.42)\end{array}$ & $\begin{array}{c}-0.027 * * * \\
(0.008)\end{array}$ & $\begin{array}{c}-0.032^{* *} \\
(0.01)\end{array}$ & $\begin{array}{c}-0.029 * * \\
(0.032)\end{array}$ \\
\hline Tuscany & $\begin{array}{l}0.014 \\
(0.26)\end{array}$ & $\begin{array}{c}0.005 \\
(0.436)\end{array}$ & $\begin{array}{c}-0.025^{* * * *} \\
(0.002)\end{array}$ & $\begin{array}{c}-0.018^{* *} \\
(0.056)\end{array}$ & $\begin{array}{c}-0.017 * * \\
(0.072)\end{array}$ \\
\hline Umbria & $\begin{array}{c}-0.002 \\
(0.796)\end{array}$ & $\begin{array}{c}0.008 \\
(0.402)\end{array}$ & $\begin{array}{c}-0.026 * * * \\
(0.002)\end{array}$ & $\begin{array}{c}-0.015^{* *} \\
(0.012)\end{array}$ & $\begin{array}{c}-0.016 * * \\
(0.018)\end{array}$ \\
\hline Lazio & $\begin{array}{l}-0.003 \\
(0.468)\end{array}$ & & $\begin{array}{c}0.009 * * \\
(0.02)\end{array}$ & $\begin{array}{c}0.009 * * * \\
(0.006)\end{array}$ & $\begin{array}{c}-0.017 * * * \\
(0.002)\end{array}$ \\
\hline Sicily & $\begin{array}{l}-0.002 \\
(0.564)\end{array}$ & $\begin{array}{l}0.002 \\
(0.76)\end{array}$ & $\begin{array}{c}0.005 \\
(0.176)\end{array}$ & $\begin{array}{c}0.019 * * * \\
(0.000)\end{array}$ & $\begin{array}{c}0.010 * * \\
(0.024)\end{array}$ \\
\hline
\end{tabular}

All models control for age and its square, gender and educational level, plus region and year fixed effects. $\tau(\mathrm{r})$ is the year of DRG adoption in region $r$, the reference category for treatment dummies is $t \leq \tau(r)-3$. Robust $p$-values in parentheses account for clustering at the region level and are obtained by wild bootstrap using 1000 repetitions. Estimates in Column 3 are derived from the 1993-1999 sample. ***, ** and * for statistical significance at the 1, 5 and 10 percent confidence level 
Table 9 (continued)

\begin{tabular}{|c|c|c|c|c|c|}
\hline & $\begin{array}{c}(1) \\
\mathrm{t}=\tau(\mathrm{r})-2\end{array}$ & $\begin{array}{c}(2) \\
\mathrm{t}=\tau(\mathrm{r})-1\end{array}$ & $\begin{array}{c}(3) \\
\mathrm{t}=\tau(\mathrm{r})\end{array}$ & $\begin{array}{c}(4) \\
\mathrm{t}=\tau(\mathrm{r})+1\end{array}$ & $\begin{array}{c}(5) \\
\mathrm{t} \geq \tau(\mathrm{r})+2\end{array}$ \\
\hline \multicolumn{6}{|c|}{ Panel C: Day Hospital (Observations= 351,700; Adj-R2=0.005) } \\
\hline Lombardy & $\begin{array}{c}0.004 \\
(0.484)\end{array}$ & $\begin{array}{c}0.001 \\
(0.702)\end{array}$ & $\begin{array}{c}-0.001 \\
(1)\end{array}$ & $\begin{array}{l}0.002 \\
(0.14)\end{array}$ & $\begin{array}{c}0.002 \\
(0.326)\end{array}$ \\
\hline Veneto & $\begin{array}{c}0.006 \\
(0.4)\end{array}$ & $\begin{array}{c}0.001 \\
(0.642)\end{array}$ & $\begin{array}{c}0.000 \\
(0.456)\end{array}$ & $\begin{array}{l}-0.006 \\
(0.288)\end{array}$ & \\
\hline Emilia-Romagna & $\begin{array}{l}-0.007 \\
(0.528)\end{array}$ & $\begin{array}{l}0.001 \\
(1)\end{array}$ & $\begin{array}{c}-0.006 * * * \\
(0.002)\end{array}$ & $\begin{array}{c}-0.010 * * * \\
(0.002)\end{array}$ & $\begin{array}{c}-0.020 * * * \\
(0.002)\end{array}$ \\
\hline Tuscany & $\begin{array}{l}-0.003 \\
(0.486)\end{array}$ & $\begin{array}{l}-0.003 \\
(0.276)\end{array}$ & $\begin{array}{l}-0.001 \\
(0.276)\end{array}$ & $\begin{array}{l}0.006^{*} \\
(0.09)\end{array}$ & $\begin{array}{l}-0.003 \\
(0.182)\end{array}$ \\
\hline Umbria & $\begin{array}{c}0.009 \\
(0.486)\end{array}$ & $\begin{array}{c}0.005 * * \\
(0.024)\end{array}$ & $\begin{array}{l}0.002 * \\
(0.074)\end{array}$ & $\begin{array}{l}-0.004 \\
(0.934)\end{array}$ & $\begin{array}{l}-0.006 \\
(0.604)\end{array}$ \\
\hline \multicolumn{6}{|c|}{ Panel D: Hospitalization (Observations $=665,660 ;$ Adj-R2=0.032) } \\
\hline Piedmont & $\begin{array}{c}0.004 \\
(0.488)\end{array}$ & $\begin{array}{c}0.004 \\
(0.486)\end{array}$ & $\begin{array}{l}-0.001 \\
(0.686)\end{array}$ & $\begin{array}{l}0.001 \\
(0.54)\end{array}$ & $\begin{array}{l}0.003 \\
(0.22)\end{array}$ \\
\hline Lombardy & $\begin{array}{c}0.004 \\
(0.572)\end{array}$ & $\begin{array}{l}-0.013 \\
(0.206)\end{array}$ & $\begin{array}{c}-0.018 * * * \\
(0.002)\end{array}$ & $\begin{array}{c}-0.008 * * * \\
(0.004)\end{array}$ & $\begin{array}{c}-0.015^{* *} \\
(0.002)\end{array}$ \\
\hline Veneto & $\begin{array}{l}-0.010 \\
(0.128)\end{array}$ & $\begin{array}{l}-0.015 \\
(0.228)\end{array}$ & $\begin{array}{c}0.000 \\
(1)\end{array}$ & $\begin{array}{c}-0.010 * * \\
(0.004)\end{array}$ & $\begin{array}{c}-0.012 * * \\
(0.008)\end{array}$ \\
\hline Emilia-Romagna & $\begin{array}{l}-0.013 \\
(0.462)\end{array}$ & $\begin{array}{l}-0.009 \\
(0.206)\end{array}$ & $\begin{array}{c}-0.023 * * * \\
(0.002)\end{array}$ & $\begin{array}{c}-0.015^{* * *} \\
(0.002)\end{array}$ & $\begin{array}{c}-0.018 * * * \\
(0.002)\end{array}$ \\
\hline Tuscany & $\begin{array}{l}-0.001 \\
(0.862)\end{array}$ & $\begin{array}{l}-0.012 \\
(0.218)\end{array}$ & $\begin{array}{c}-0.026 * * * \\
(0.002)\end{array}$ & $\begin{array}{c}-0.006 * * \\
(0.034)\end{array}$ & $\begin{array}{c}-0.015^{* * * *} \\
(0.002)\end{array}$ \\
\hline Umbria & $\begin{array}{l}0.015 \\
(0.53)\end{array}$ & $\begin{array}{c}0.005 \\
(0.754)\end{array}$ & $\begin{array}{l}-0.007 \\
(0.636)\end{array}$ & $\begin{array}{l}-0.007 \\
(0.812)\end{array}$ & $\begin{array}{c}-0.003 \\
(1)\end{array}$ \\
\hline Lazio & $\begin{array}{c}0.002 \\
(0.582)\end{array}$ & & $\begin{array}{c}0.004 * * \\
(0.02)\end{array}$ & $\begin{array}{l}0.005 \\
(0.17)\end{array}$ & $\begin{array}{c}0.001 \\
(0.536)\end{array}$ \\
\hline Sicily & $\begin{array}{l}-0.002 \\
(0.606)\end{array}$ & $\begin{array}{c}0.006 \\
(0.504)\end{array}$ & $\begin{array}{c}0.015 * * * \\
(0.000)\end{array}$ & $\begin{array}{c}0.009 * * * \\
(0.000)\end{array}$ & $\begin{array}{c}0.010 * * * \\
(0.000)\end{array}$ \\
\hline \multicolumn{6}{|c|}{ Panel E: Satisfaction if hospitalized (Observations= 34,726; Adj-R2=0.071) } \\
\hline Piedmont & $\begin{array}{c}0.044 \\
(0.334)\end{array}$ & $\begin{array}{l}-0.036 \\
(0.652)\end{array}$ & $\begin{array}{c}0.017 \\
(0.506)\end{array}$ & $\begin{array}{l}-0.020 \\
(0.462)\end{array}$ & $\begin{array}{c}-0.089 * * * \\
(0.002)\end{array}$ \\
\hline Lombardy & $\begin{array}{l}-0.091 \\
(0.114)\end{array}$ & $\begin{array}{l}-0.024 \\
(0.574)\end{array}$ & $\begin{array}{c}-0.094 * * * \\
(0.004)\end{array}$ & $\begin{array}{l}-0.008 \\
(0.296)\end{array}$ & $\begin{array}{c}-0.061 * * * \\
(0.002)\end{array}$ \\
\hline Veneto & $\begin{array}{c}0.039 \\
(0.288)\end{array}$ & $\begin{array}{c}0.024 \\
(0.514)\end{array}$ & $\begin{array}{l}0.008 \\
(0.39)\end{array}$ & $\begin{array}{c}-0.001 \\
(1)\end{array}$ & $\begin{array}{l}-0.029 \\
(0.34)\end{array}$ \\
\hline Emilia-Romagna & $\begin{array}{l}-0.017 \\
(0.158)\end{array}$ & $\begin{array}{c}0.004 \\
(0.732)\end{array}$ & $\begin{array}{c}-0.067 * * \\
(0.034)\end{array}$ & $\begin{array}{c}-0.060 * * * \\
(0.002)\end{array}$ & $\begin{array}{c}-0.080^{* * * *} \\
(0.002)\end{array}$ \\
\hline Tuscany & $\begin{array}{l}0.059 \\
(0.87)\end{array}$ & $\begin{array}{c}0.026 \\
(0.458)\end{array}$ & $\begin{array}{c}0.102^{* * * *} \\
(0.006)\end{array}$ & $\begin{array}{l}-0.026 \\
(0.928)\end{array}$ & $\begin{array}{l}0.020^{*} \\
(0.094)\end{array}$ \\
\hline Umbria & $\begin{array}{c}0.026 \\
(0.862)\end{array}$ & $\begin{array}{l}-0.023 \\
(0.556)\end{array}$ & $\begin{array}{c}0.165^{* * * *} \\
(0.000)\end{array}$ & $\begin{array}{l}-0.020 \\
(0.442)\end{array}$ & $\begin{array}{l}-0.025 \\
(0.432)\end{array}$ \\
\hline Lazio & $\begin{array}{c}0.027 \\
(0.412)\end{array}$ & & $\begin{array}{c}0.052^{* * * *} \\
(0.000)\end{array}$ & $\begin{array}{c}0.049^{* *} \\
(0.044)\end{array}$ & $\begin{array}{c}0.038^{* *} \\
(0.012)\end{array}$ \\
\hline Sicily & $\begin{array}{l}0.059 \\
(0.31)\end{array}$ & $\begin{array}{c}0.085 \\
(0.334)\end{array}$ & $\begin{array}{c}0.092^{* * * *} \\
(0.002)\end{array}$ & $\begin{array}{c}-0.064 * * \\
(0.048)\end{array}$ & $\begin{array}{l}-0.020 \\
(0.666)\end{array}$ \\
\hline
\end{tabular}


Figure 1: Evolution of average individual outcomes by treatment status

a) Self assessed health

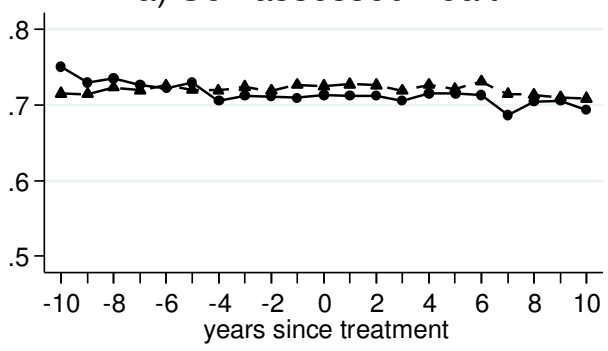

c) Hospitalization

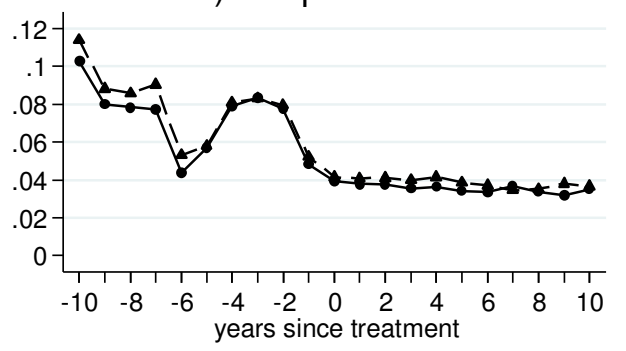

b) Emergency room

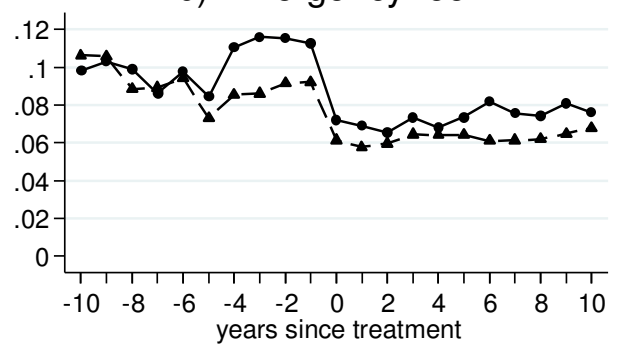

d) Day hospital

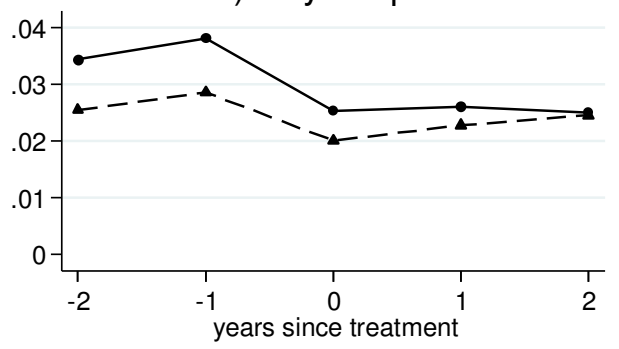

Treated - - - - Controls 